University of Texas Rio Grande Valley

ScholarWorks @ UTRGV

\title{
If You Can't Take the Heat: Cultural Beliefs about Questionable Conduct, Stigma, Punishment, and Withdrawal among Mexican Police Officers
}

Jorge A. Gonzalez

The University of Texas Rio Grande Valley

Lorena R. Pérez-Floriano

Follow this and additional works at: https://scholarworks.utrgv.edu/mgmt_fac

Part of the Business Administration, Management, and Operations Commons, and the Other Public Affairs, Public Policy and Public Administration Commons

\section{Recommended Citation}

Gonzalez, J. A., \& Pérez-Floriano, L. R. (2015). If You Can't Take the Heat: Cultural Beliefs about Questionable Conduct, Stigma, Punishment, and Withdrawal among Mexican Police Officers. Organization Studies, 36(5), 665-687. https://doi.org/10.1177/0170840615571961

This Article is brought to you for free and open access by the Robert C. Vackar College of Business \& Entrepreneurship at ScholarWorks @ UTRGV. It has been accepted for inclusion in Management Faculty Publications and Presentations by an authorized administrator of ScholarWorks @ UTRGV. For more information, please contact justin.white@utrgv.edu,william.flores01@utrgv.edu. 
If you can't take the heat: Cultural beliefs about questionable conduct, stigma, punishment, and withdrawal among Mexican police officers

Dysfunctional misconduct is a problem in many occupations, corporations, and public organizations. Research has shown that emergence, diffusion, and normalization of misconduct depends upon organizational dynamics (Ashforth, Gioia, Robinson, \& Treviño, 2008; Linstead, Maréchal, \& Griffin, 2014; Pinto, Leana \& Pil, 2008), as well as the occupational and cultural context that surrounds such behavior (Bond et al., 2004; Jong-Sung \& Khagram, 2005; Schein, 2006; Treviño, Weaver, \& Reynolds, 2006).

In this study, we explore the prevalence and outcomes of cultural beliefs about questionable conduct and the awareness of a corrupt stigma. Research shows that stigma awareness can stimulate disidentification and withdrawal from a stigmatized group (Lai, Chan, \& Lam, 2013; Major \& O’Brien, 2005). Paradoxically, stigma also fosters group identification and solidarity (Ashforth \& Kreiner, 1999), particularly when it is hard to leave a group. Applying theory from occupational stigma (Ashforth \& Kreiner, 1999; Pinel, 1999) and organizational culture (Hofstede, 1998; Schneider, 1987; Schein, 2006), we surmise that stigma consciousness acts as a catalyst by justifying cultural beliefs that rationalize misconduct. Policing has a "dirty work" stigma (Ashforth \& Kreiner, 1999) characterized by corruption, coercion, violence, and contact with criminals (Dick, 2005; Punch, 2003; Rubinstein, 1973). We conducted this study in a setting rife with violence and corruption: The police force of a Mexican border city.

We employed a mixed methods design (Creswell \& Plano Clark, 2011; Tashakkori \& Teddlie, 2010) intended to ease potential methodological problems. Misconduct and stigma have a "dark" and "subterranean" nature, and their study presents issues with access, respondent sincerity, fear of repercussion, social desirability, and self-serving bias (Linstead et al., 2014; 
Skogan \& Frydl, 2004). These obstacles are greater in developing countries (Ivkovic, 2005), added to troubles with the meaning and translation of Western instruments (Schaffer \& Riordan, 2003). Further, we integrate quantitative and qualitative methods to examine local phenomena in a context-oriented manner (Peterson \& Søndergaard, 2011; Welch, Piekkari, Plakoyiannaki, \& Paavilainen-Mäntymäki, 2011). In the qualitative phase, we explored the prevalence and meaning of occupational stigma and beliefs about questionable conduct. The results helped us in the development of a culturally-relevant scale of beliefs comprised by cultural artifactsproverbs reflecting common folk wisdom (Leung et al., 2002; Shapin, 2001; Weber, Hsee, \& Sokolowska, 1988; Yau, 1994). For the quantitative phase, we used survey and objective data to assess the interactive role of cultural beliefs and stigma on two sets of outcomes - reprimands, a coercive form of persuasion managers use to stimulate conformity or withdrawal (Podsakoff, Bommer, Podsakoff, \& MacKenzie, 2006; Schein, 2006), and withdrawal behavior, which we operationalized as absenteeism and turnover.

Paying attention to context (Tsui, 2007), we begin by describing the relevance of stigma and corruption to the occupational, organizational, and national milieu. We then discuss pertinent theory on dysfunctional misconduct (Ashforth \& Anand, 2003; Greve, Palmer, \& Pozner, 2010), cultural beliefs (Leung et al., 2002), and occupational stigma (Pinel \& Paulin, 2005), and present our hypotheses. Subsequently, we discuss the methods and results.

\section{Occupational, organizational, and national context}

Misconduct and corruption are common to the police around the world (Frühling, 2007;

Newburn \& Webb, 1999; Rubinstein, 1973), and ascribe the occupation with a negative stigma. These problems are more prevalent in developing economies (Ivkovic, 2005), where the police 
also face greater exposure to crime, danger, and violence, as well as lower pay and access to quality equipment (LaRose \& Maddan, 2009; Sabet, 2012; Uildriks, 2010). For instance, the Mexican police face a high degree of danger and crime impunity (Daly, Heinle, \& Shirk, 2012). Qualitative studies of the Mexican police depict a strong culture and adverse occupational characteristics (Azaola, 2009; Botello \& Rivera, 2000; Suárez de Garay, 2005). These studies describe a complex culture of organized chaos characterized by solidarity, secrecy, and mutual reliance, but also a strict hierarchical structure, unfair management, and a competitive climate (Botello \& Rivera, 2000; Costas \& Grey, 2014; Uildriks, 2010). They document deficient working conditions, including the need for some officers to personally buy life jackets, bullets, and patrol car gasoline.

The organizational attributes these studies mentioned above describe is close to the notions of thoroughly corrupt organizations, where people engage in corruption for both personal and organizational benefit (Pinto et al., 2008), and organizational miasma - a contagious state of darkness and pollution characterized by corruption, silence, lack of resistance, and a porous boundary between public and private life, among other problems (Gabriel, 2012). Officers rationalize and justify corruption with their low pay and by blaming civilians. For example, the dysfunctional practice of withholding effort is illustrated with the dictum "if you want to become an old cop, play dumb," a word-play on a Spanish proverb stating that people who follow advice live longer. Examples of institutionalized misconduct include the "mordida" (verbatim: bite)—bribery involving shared responsibility by the person who gives it and the one who receives it—(Bailey \& Paras, 2006; Suárez de Garay, 2005), sharing bribes with supervisors, and paying them for lucrative assignments (Botello \& Rivera, 2000). These studies show that corruption is prevalent, but condoned when performed within organizational norms 
and for the organization's benefit. Nonetheless, severe misconduct carried for personal benefit (e.g. collaborating with organized crime) is not considered an institutionalized practice. If caught, it can lead to repercussions such as being reprimanded, discharged, indicted, imprisoned, and even brutalized in the process (Uildriks, 2010).

Socialization processes into unethical cultures can shape the values and moral judgment of new entrants (Kammeyer-Mueller, Simon, \& Rich, 2012; Treviño et al., 2006). Similar to their rich-nation counterparts (Britz, 1997; Van Maanen, 1975, 1978), Mexican police officers go through harsh socialization processes in the academy and their organizations. Due to occupational stigma, many face a lack of societal integration. They feel trapped and to lack behavioral and occupational alternatives (Azaola, 2009; Botello \& Rivera, 2000). The metaphor of being "enrejados" (behind bars) like the criminals they have caught describes their need to comply with institutionalized authority that condemns them to complicit impunity (Suárez de Garay, 2005). Despite these problems, many officers describe the uniform's strong symbolic value and high occupational identification. This echoes Western studies showing that police stigma is related to withdrawal, but also solidarity and group identification (cf. Lester \& Brink, 1985; Perrott \& Taylor, 1994; Trostle, 2005; Westmarland, 2005).

Moreover, the police organization is embedded in a rigid political system of institutionalized secrecy (Arellano-Gault \& Lepore, 2011). Organizational culture dynamics and coercive persuasion are powerful (Azaola, 2009; Botello \& Rivera, 2000), as it is very hard to leave the group (Schein, 2006). Rank officers endure the adverse stigma, but a collective and high power distance Mexican culture emphasizing hierarchy and subculture distinctions (Hofstede, 1998; Trice, 1993) shields high-status administrators. 


\section{Theoretical background}

\section{Normalized and deviant misconduct}

Scholars distinguish across deviant, dysfunctional, and corrupt behavior to examine their antecedents and outcomes. Deviant behavior refers to aberrant conduct that violates organizational norms and threatens its well-being (Robinson \& Bennett, 1995). It can be constructive or destructive (Warren, 2003). In contrast, dysfunctional behavior can stem from institutionalized practices that actually are common. Thus, workplace deviance refers to divergence from norms that may or may not be dysfunctional (Griffin \& Lopez, 2005).

Corruption refers to the illicit use of position or power for personal or collective gain. It implies a willful perversion of morals, order, and ideals (Ashforth et al., 2008). Corruption can be embedded in organizational processes and routines (e.g., Ashforth \& Anand, 2003; Sarchione, Cuttler, Muchinsky, \& Nelson-Gray, 1998). People are "infected” or initiate, perpetuate, and succumb to corruption through coercion, or by condoning and complying with dysfunctional practices (Pinto et al., 2008). Attraction-selection-attrition forces (Schneider, 1987) drive people to self-select and be socialized into corrupt settings, while misfits are selected out. Supervisors have an important role as they model (un)ethical behavior to subordinates (Treviño et al., 2006).

Dysfunctional behavior thus includes corrupt behavior that does not deviate from institutional norms (e.g. whistle-blowing is deviant, but not corrupt; Park, Blenkinsopp, Oktem, \& Omurgonulsen, 2008). Corrupt behavior is dysfunctional to society, but can benefit the organization and/or the perpetrator (Linstead et al., 2014; Pinto et al., 2008). Therefore, we term dysfunctional and corrupt behavior accepted by the organization normalized misconduct and dysfunctional and corrupt behavior going beyond institutionalized norms deviant misconduct. Misconduct, punishment, and withdrawal behavior 
Punishment is an exercise of coercive power. It consists of the administration of negative consequences to modify undesired behavior (Arvey \& Ivancevich, 1980; Butterfield, Treviño, \& Ball, 1996; Treviño et al., 2006). Research on workplace punishment is scant as many scholars consider it unfair, harsh, as well as ineffective as it has unintended adverse consequences such as absenteeism and turnover (Podsakoff et al., 2006). Others consider its ineffectiveness to be a misconception (Atwater, Waldman, Carey, \& Cartier, 2001). Punishment is common in the police and militarized organizations (Cancino \& Enriquez, 2004; Godfrey, Lilley, \& Brewis, 2012; Gordon, Clegg \& Kornberg, 2009). It is often implemented to correct misconduct, but it is also used to coerce people into compliance with normalized misconduct.

\section{Cultural beliefs about questionable conduct}

Corruption is influenced by a nations' political, economic, institutional (Jong-Sung \& Khagram, 2005) and cultural environment (Husted, 2002; Sanchez, Gomez, \& Wated, 2008). Culture includes values, norms, traditions, assumptions, and beliefs (Hofstede, 1998). This last element refers to convictions about the truth or reality of a phenomenon. Cultural beliefs are the basis for assumptions (Schein, 2006) and are conducive to behavior and rationalizations for such behavior. Bond et al. (2004) advanced the concept of social axioms - the "basic premises that people endorse and use to guide their behavior in different situations" (p. 288) - to refer to beliefs about "the way things are" or how the world works (Leung et al., 2002).

We studied beliefs related to the prevalence, justification, and rationalization of misconduct in this national, occupational, and organizational context. First, we considered cultural beliefs about greed - an excessive desire for more of something (Wang \& Murnighan, 2011), such as monetary gain. This belief reflects the idea that money is a valuable and powerful resource regardless of the means used to obtain it, and that people with money are admirable and 
deserve it. Greed is related to ambition, but implies avarice. Greed can elicit unethical behavior when people are exposed to opportunities for monetary gain (Gino \& Pierce, 2009; Kouchaki, Smith-Crowe, Brief, \& Sousa, 2013).

Second, we considered cultural beliefs about wariness - the notion that people should be cautious of out-group members and that silence and secrecy about misconduct is desirable. Wariness may stem from the need to comply with perceptions of cultural norms (Costas \& Grey, 2014; Park et al., 2008) and condone the misconduct of others (Gabriel, 2012). Wariness can reflect group loyalty used to promote and obtain benefits, such as protection and solidarity (Bittner, 1970; Van Maanen, 1978).

Third, we considered toughness, which entails beliefs in roughness and brute force to accomplish goals, and the virtuousness of courage and valor to withstand danger. Toughness is similar to rugged individualism, a coping strategy common among police officers (Beehr, Johnson, \& Nieva, 1995). It resembles the Mexican value of “machismo," which equates fearlessness, toughness, and bravado with masculinity (Paredes, 1971). Although bravery, courage, and valor have positive connotations, toughness can degenerate into ruthlessness, cruelty, and brutality.

Fourth, we considered savvy, which refers to beliefs about the importance of personal wit and being "street-smart." Savvy is related to the use of manipulation to obtain and power and influence, and the exercise of authority through "palancas" (verbatim: leverage) or influential personal connections. Both are common in police organizations (Bittner, 1970). Although potentially positive, savvy can degrade into cunning and guile.

These beliefs are neither exhaustive nor unique to the present study's setting. Greed is common in other masculine cultures (Hofstede, 1998). Savvy is similar to practices such as the 
jeithino in Brazil (Duarte, 2006), guanxi in China (Xin \& Pearce, 1996), and machiavellianism, which is universal. Toughness is common in assertive and masculine cultures (Aditya \& House, 2002; Hofstede, 1998), "cultures of honor" such as the American south (Cohen, Nisbett, Bowdle, \& Schwarz, 1996), and military occupations (Godfrey et al., 2012). Lastly, wariness is common in high-power distance (Park et al., 2008) and secretive cultures (Costas \& Grey, 2014).

We surmise that these four cultural beliefs are related to individual adherence to organizational norms. As we describe later, three of these beliefs conform to police organizational and occupational normative expectations. Toughness, greed, and wariness are expected in an organization dealing with constant danger, where people need to cover for one another, and where money on-the-side is considered the only way to earn a living. People with such beliefs fit the organization better and face lower attrition pressures. Thus, they are less likely to distance themselves from the organization through absenteeism or to leave it, either voluntarily or involuntarily.

Hypothesis 1: Cultural beliefs about questionable conduct related to greed, toughness, and wariness will have a negative effect on (a) reprimands, (b) absenteeism, and (c) turnover.

Beliefs about savvy, however, may lead to reprimands and withdrawal behavior. Savvy may help new recruits learn on the street faster and use the cultural structure to their advantage. However, people who believe in savvy are likely to rely on individual abilities to manage adversity, and to take advantage of questionable opportunities for individual rather than group gain. Savvy and cunning are considered positive leadership attributes in Mexico and Latin America (Aditya \& House, 2002). Nonetheless, savvy may not be desirable or tolerated from rank-and-file employees in high power distance and collective cultures. Moreover, organizational members in low hierarchical roles are expected to display greater norm conformity or risk being 
perceived as deviant (Bowles \& Gelfand, 2010). Therefore, those who are savvy or cunning may be thought to be different, "too smart for their own good," and to fail to comply with normalized misconduct norms. For example, savvy rank officers may be considered the ones who engage in deviant misconduct and threaten the organization's welfare.

Hypothesis 2: Cultural beliefs about questionable conduct related to savvy will have a positive effect on (a) reprimands, (b) absenteeism, and (c) turnover.

Awareness of a dirty work stigma

Dirty work refers to occupational activities considered to be disgusting or degrading (Ashforth \& Kreiner, 1999). People who perform "dirty" jobs are tainted by others who seek to distance themselves from such activities. Researchers have identified three types of occupational stigmas: The moral taint of dubious ethics (e.g. exotic dancer, pawnbroker), the physical taint of danger or contact with physical or symbolic "dirt" (e.g. miner, garbage collector), and the social taint of contact with other stigmatized people (e.g. prison guard) (Ashforth \& Kreiner, 2014). Policing possesses the three components due to its danger, corruption, brutality, violence, and contact with criminals (Dick, 2005; Drew \& Hulvey, 2007; Rubinstein, 1973).

Stigma consciousness refers to awareness and sensitivity to a stereotyped status (Pinel \& Paulin, 2005). It influences behavior given the importance of occupation to people's selfconcepts. People identify less and are more likely to leave jobs with a dirty-work stigma (Lai et al., 2013), but those who cannot distance themselves from a stigma (e.g. due to low job alternatives or sunk costs) may embrace the stigma to maintain self-esteem (Crocker \& Major, 1989; Goffman, 1963). They can rely on social validation from others in the same situation, construct a positive identity, and protect themselves from identity threat and marginalization. They may reframe or change the meaning attached to the occupation, recalibrate the standards 
used to judge it, and refocus their attention to other occupational attributes (Ashforth \& Kreiner, 1999). These identity strategies, common in police organizations (Lester \& Brink, 1985; Perrott \& Taylor, 1994; Pinel \& Paulin, 2005), allow the emergence of strong occupational cultures, occupational and organizational identification, and stigmatized group solidarity and norm conformity (Kreiner, Ashforth, \& Sluss, 2006; Manning, 2008).

As occupational dirty-work stigmas can lead to withdrawal but also solidarity and identification, we do not hypothesize a main effect but explore stigma consciousness as a moderator. We posit that people who are more conscious of the police stigma are likely to comply with organizational expectations, including condoned normalized misconduct, and to justify such behavior. Relying on the premise that beliefs and attitudes interact to influence behavior (Bond et al., 2004; Pinel, 1999), we surmise that the role of beliefs about questionable conduct on withdrawal behavior and reprimands is contingent upon stigma consciousness.

Hypothesis 3: Stigma consciousness will moderate the relationship between beliefs about greed on (a) reprimands, (b) absenteeism, and (c) turnover reprimands such that a negative relationship will be stronger among those with higher stigma consciousness. Hypothesis 4: Stigma consciousness will moderate the relationship between beliefs about toughness on (a) reprimands, (b) absenteeism, and (c) turnover such that a negative relationship will be stronger among those with higher stigma consciousness.

Hypothesis 5: Stigma consciousness will moderate the relationship between beliefs about wariness on (a) reprimands, (b) absenteeism, and (c) turnover such that a negative relationship will be stronger among those with higher stigma consciousness.

As stated earlier, organizational members may consider savvy in rank employees to be guile or cunning. People who are stigma conscious and who possess savvy beliefs may be less 


\begin{abstract}
likely to perceive the bonding effects of stigma given that they may have (or believe to have) the ability to exit the group. They are likely to distance themselves from the identity rather than to display group identification and solidarity, conform to social expectations, or be considered team players. As such, they may deviate from established norms, withdraw, and receive punishments.

Hypothesis 6: Stigma consciousness will moderate the relationship between beliefs about savvy on (a) reprimands, (b) absenteeism, and (c) turnover such that a positive relationship will be stronger among those with higher stigma consciousness.
\end{abstract}

\title{
Method
}

Following mixed-method design recommendations (Cassell \& Symon, 2004; Creswell \& Plano Clarck, 2011; Tashakkori \& Teddlie, 2010), we carried the qualitative and quantitative study phases for complementarity and development purposes. This included reflecting upon ongoing results and using findings from one method to inform the issues raised by the other. The qualitative and attitudinal quantitative data were collected in 2006, which coincided with the start of the Calderon presidential administration in Mexico and an intensification of the drug war.

\section{Qualitative phase}

In this phase, we explored the presence and implications of institutionalized beliefs about danger, stigma, and misconduct. We sought to identify and narrow the research focus, develop measurement instruments, and illustrate and interpret quantitative findings (Creswell \& Plano Clark, 2011). We used semi-structured interviews. Participants were recruited from a group of organizational members receiving coaching from the second author as part of an administrationinitiated change intervention. We implemented purposive (theoretical) sampling. Given potential 
gender differences and the formation of subcultures across hierarchical roles (Prenzler \& Drew, 2013; Trice, 1993), we further set a premium on gender and role diversity to obtain a broad range of experiences (Cassell \& Symon, 2004). We recruited to the point of redundancy—when we expected no new information from subsequent participants. Ten officers - three male administrators and seven municipal officers (including three female officers) — were interviewed. The second author conducted the interviews. Using an interpretive approach, we assessed the responses to find common patterns and themes (Bluhm, Harman, Lee, \& Mitchell, 2011). To be reflective (Cassell \& Symon, 2004), both authors engaged in an ongoing discussion of the responses to critically assess the research process and question presuppositions. For example, we disregarded an initial emphasis on crime risk as precursor to withdrawal as we found that respondents were well aware of occupational risks and self-selected into a dangerous occupation. Although not part of the research design, we were able corroborate our results and interpretations with a few police administrators during a formal presentation of the results.

Respondents were initially asked about satisfying and dissatisfying aspects of the job. Interview questions then turned to relevant thoughts and experiences on occupational attributes emphasized in the literature, such as socialization, "real police work," and "learning on the street" (Van Maanen, 1978). Interview themes were allowed to deviate to give voice to the interviewees and focus on their experience. Interviewees were not directly asked about corruption and danger due to their sensitive nature, but these themes surfaced naturally.

The information gathered helped us understand the relevance of withdrawal behavior in this culture and to interpret objective quantitative data. Responses suggested that the receipt of formal reprimands itself may be subject to questionable practices such as cronyism and favoritism by police superiors, who may pardon or "bend the rules" for officers who are well 
socialized or liked. Also, police administrators commented about sales of excused absences, which we corroborated with local newspaper articles reporting that local state-hospital physicians were caught selling formal sick-leave to police officers.

Responses revealed that officers were aware of their corrupt and violent stigma, but that those who were ashamed of their occupation were shunned or informally penalized by colleagues. Respondents justified questionable conduct, blaming civilians, and the idea of stigma as the precursor of a self-fulfilling prophecy resonated with interviewees.

"If they put all corrupt people in jail, who would lock the cell?" "If you [society] tell me that I am [corrupt], then I am."

"If the officer never asks for money and the citizens offer it, who is the corrupt one?"

The idea of toughness arose from the discussion of risk, courage, and "real police work." Contrary to initial expectations, danger was not deemed a negative occupational attribute, and most respondents described the importance of toughness, bravery, and valor. Bravery was equated to masculinity, a "professional badge," and what it takes to enter an inner-circle.

"Becoming one of the guys requires behaving like a real man."

Respondents manifested that being weak or showing fear was despised. Three officers described the story of a colleague who would freeze in encounters when others expected him to cover them. He was blamed for the decease of former partners and earned social rejection, illustrated by being nicknamed an animal that plays dead when facing danger:

“The 'zarigüeya' [possum] killed three of his partners."

Interviewees described the importance of courage in the attraction and retention of police officers. One female officer described a criminal chase and cross-fire that required her to slide under a Van with the motor running. Her feelings about the episode were positive: 
"I felt the adrenaline rush. At that moment I realized that this [being a police officer] was what I wanted to do for the rest of my life."

Some respondents confounded bravado, courage, and toughness with ruthlessness, violence, and lack of mercy. This was justified by the behavior being common and by the guilt of presumed criminals:

“...we go to 'el bordo' to pick up bums [most are homeless or drug addicts deported from the U.S.] ... Do I like going? Are you kidding? I love it! We go on the pick-up trucks, chase them like rabbits, give them a scolding, and 'pa' dentro' [on to detention]."

The use of proverbs to justify and explain behavior resonated with interviewees. For instance, respondents reiterated a common Mexican proverb used to describe how officers learned through socialization, including the spread of misconduct and social stigma. This proverb equates institutionalized cheating and learning to cheat to teamwork, consistent with Mars' (1982) animal metaphors distinguishing workplaces "cheats" based on how they learn and justify misconduct:

"He who hangs out with wolves learns to howl."

The consequences of the stigma were known, but interviewees also described love for the uniform and strong occupational identification. A police administrator stated that there is no choice but to love what they do because there are few alternatives:

"Becoming a cop implies entering an industry loaded with opprobrium... if an officer wants to change occupation, he [or she] will be told 'you were a police officer, [you will not get this job because] we want honest people'... If you worked in the 'ministerio público' [courthouse] you can't become a judge even though police work is the natural [job] training because we are considered to be 'rats' [thieves] ... it's because of the police image that [rank officers] can't take other jobs. This leads them to do [corrupt] things."

Another administrator indicated that the officers who are the most committed and cope with adversity are those who join the force due to family tradition and are pre-socialized by families. Others supported this:

"My wife divorced me, she could not put up with this. We moved from our house when the violence got bad, cars would stop in front every other night and make screeching tire noises... 
but my father was a cop and me and my brothers were always more serious [about being police officers] than others... I am also worried about my kids and tell them to be careful."

Being socialized and learning from one another was a common theme, but also the reason some "go to the other side" or engage in deviant misconduct. In contrast to other beliefs, respondents perceived savvy to be negative and equated it to being "tranza" [displaying cunning and guile] and earning the group's rejection:

"When someone goes to the other side, other people shun him [or her]"

"One year [Jane Doe] was given a medal for being the best police officer in the corporation... A couple of years later she died in jail. She was the commander's pet, but she got involved with heavy 'narcos' and things got rough for her when [police leadership] changed."

A few officers stated that "everybody" was involved in violence or corruption, but also that some officers take pride in their ethics and value of the uniform. To show occupational pride, some officers described an episode when rank officers were deprived of their guns during a corruption investigation. This led to protests, including officers who brought slingshots to work and posed with them for newspaper photos.

Overall, respondents described the presence of corrupt conduct and questionable behavior involving greed, toughness, wariness, and savvy. They described rationalizations through the description of dirty-work attributes in other occupations (e.g. politics, law, finance) and the role of civilians in bribery. Similar to the idea of corruption in pursuit of a noble cause (Wolfe \& Piquero, 2011), respondents argued that questionable conduct ultimately helps society, regardless of the means. In contrast, another officer described how he fought the stigma via reframing and recalibrating (Ashforth \& Kreiner, 1999) by enhancing occupational ends and means, but not at the expense of others.

"One evening, my partner and I found a couple stranded on the highway with car problems. We approached them and the woman became nervous and asked us to leave... but we helped them and managed to restart their car [which had California license plates]. They were 
grateful and insisted on giving us money, and we said no. They apologized and said they had heard many bad stories about us [Mexican police] and thought we were not going to be any different. We left and I felt very good about changing their attitude towards us."

\section{Quantitative phase}

We gathered quantitative data using a convenience sample. The results of the qualitative study helped the design of this phase and the interpretation of its results. Approximately 600 municipal police officers (constituted by about 2500 members) were provided with a copy of the survey and asked to complete it. We offered either anonymity or confidentiality. 352 officers returned the survey, including 41 police administrators provided with anonymity. Men comprised $92 \%$ ( $\mathrm{n}=$ $320)$ of the total sample. The average age was $32(\mathrm{SD}=7.59)$ and the average tenure was 7.44 (SD $=6.79$ ). For the hypotheses tests, we used the sample of 192 rank officers opting for confidentiality We did not find any significant differences in cultural beliefs or stigma consciouness between rank officers who selected confidentiality and those who selected anonymity.

Reprimands. Received reprimands represent formal reports of misconduct deemed by the police administration to deserve further inquiry. Reprimands are given due to citizens' complaints for corruption or human rights' abuses, criminal investigations, or supervisor reports. Subsequent consequences depend on investigation outcomes and may consist of a warning, suspension without pay, incarceration (up to 72 hours), definite dismissal, or a criminal process. We used total reprimands in the year of data collection. Reprimands were given to 74 officers in the sample and ranged from 1 to $11($ mean $=1.18, \mathrm{SD}=1.79)$.

Withdrawal behavior (absenteeism and turnover). We measured absenteeism and turnover using objective data provided by the organization. For absenteeism, we used a logarithmic transformation of the sum of reported absent sick days during the year to normalize the data. We 
assessed turnover using organizational records. We used a three-year lag due to the low rates of exit in the occupation and nation. 55 officers left the organization.

Mexican cultural beliefs about questionable conduct (MCBQC). We developed the MCBQC scale to assess the extent to which people believe that behavior with questionable ethical underpinnings is widespread among their peers and community and represent life or "the way things are.” The scale consists of common Mexican proverbs (Pérez Martínez, 2002). Adages, sayings, or proverbs are objective cultural artifacts and examples of folk wisdom used by members of a culture to communicate common sense and experiential knowledge to one another. As such, they express societal norms and values (Sellers, 1994). Proverbs can be used to rationalize questionable behavior since they are dicta or rule-like propositions that shape judgment and guide conduct (Shapin, 2001). Researchers have used them as objective measures of culture, value orientation, and risk-taking behavior (Weber et al., 1988).

Several proverbs were retrieved from a dictionary of Mexican proverbs (Pérez Martínez, 2002). We selected 150 proverbs relevant to cultural beliefs about dysfunctional misconduct and general work-related issues. We included proverbs resembling Bond et al's (2004) “societal cynicism" belief. We used a pilot study involving 630 Mexican college students to gauge clarity, recognition, and relevance to stigma, misconduct, and danger. We selected 48 proverbs from this pilot study, including 30 proverbs judged to be related to these issues based on pilot comments and author agreement, and 18 general work-related proverbs. A second pilot study of 171 Mexican working professionals was used to corroborate the results. A preliminary exploratory factor analysis involving the two pilot study samples yielded four factors (greed, toughness, wariness, and savvy) (eigenvalues $>1.0$ ) explaining $53 \%$ of the variance. 
The final MCBQC scale focuses on proverbs related to beliefs about ethics, misconduct, and a certain disdain about "the way things are." We included the 48 proverbs (including workrelated proverbs) in the final scale to present it as an assessment of how proverbial wisdom reflects reality. The participants were instructed: "Think of your daily life as a police officer and resident of (your city) and indicate how much you agree (5) or disagree (1) with the following proverbs.” An option for not understanding a proverb was provided, but no one selected it.

We conducted an exploratory factor analysis with varimax rotation of the 30 relevant proverbs and retained 22 proverbs loading in 4 factors (greed, wariness, toughness, and savvy) explaining $53 \%$ of the variance. The final scale is shown in the appendix, and reliabilities are reported in table 1. We explored convergent validity using Rosenbaum and Kuntze's (2003) measure of anomie, which assesses disdain for human nature and mistrust in social institutions. Anomie was related to greed $(r=0.45, \mathrm{p}<.001)$, toughness $(\mathrm{r}=0.36, \mathrm{p}<.001)$, wariness $(\mathrm{r}=$ $0.40, \mathrm{p}<.001)$, and savvy $(\mathrm{r}=0.35, \mathrm{p}<.001)$.

We further conducted a CFA with maximum likelihood estimation using AMOS. The four-factor model showed good fit using recognized standards $\left(\chi^{2}[197]=382.00, p<.001\right.$, the comparative fit index $=.93$, root mean square error of approximation $=.05$, standardized root mean square residual $=.05)$. All indicator items loaded significantly on their specified latent construct. Standardized factor loadings ranged from .53 to .75 , averaging .62 . This model showed superior fit than several alternative models, including a single-factor model $\left(\chi_{\text {diff }}^{2}[6]=\right.$ $64.45, p<.001$ ), a three-factor model where the covariance between toughness and savvy was fixed to one $\left(\chi_{\text {diff }}^{2}[1]=16.89, p<.001\right)$, and all other possible three-factor models.

Stigma consciousness. We modified three items from Pinel's (1999) stigma consciousness scale: "Most people believe that police officers are dishonest," "People from (city) see the police as an 
outsider army," and "people in (city) do not respect police officers". We complemented them with three proverbs implying that some people suffer stigmatization: "He who hangs out with wolves learns to howl," "there are no poor people with bad intentions," and "he who does the most is thanked the least." The scale showed adequate reliability $(\alpha=.70)$. A principal component analysis yielded a single component. In support of convergent validity, this measure was related $(\mathrm{r}=0.21, \mathrm{p}<.001)$ to anomie.

Controls. We controlled for tenure and gender on all outcomes, as they could affect results (Godfrey et al., 2012; Prenzler \& Drew, 2013). We also controlled for workplace injury on absenteeism and turnover using a self-reported statement. $24 \%$ of officers reported having been injured while on duty.

\section{Results}

Descriptive statistics and correlations are presented in table 1. Correlations and preliminary analyses helped our results interpretation. Tenure and greed were significantly correlated, suggesting that those who have been in the organization longer have become greedier (or believe greed is commonplace). Savvy was significantly correlated with age $(\mathrm{r}=.13, \mathrm{p}<.05)$, but not with tenure. Police supervisors held stronger beliefs in greed $($ Means $=2.45,2.14, \mathrm{t}=1.98, \mathrm{p}<$ .05 ) and marginally significant stronger beliefs in toughness (Means $=3.17,2.65, \mathrm{t}=1.77, p<$ $.10)$ and wariness $($ Means $=3.30,2.87, \mathrm{t}=1.87, p<.10)$. This suggested that administration and rank officers were different subcultures, and that rank officers could be socialized through topdown processes. Savvy beliefs were relatively high for both roles. Moreover, a culture equating toughness with masculinity may have been harsher for women. Gender was significantly correlated with turnover, indicating that women were more likely to leave despite having 
marginally significant $(p<.10)$ lower stigma consciousness than men. We did not find significant gender differences in cultural beliefs.

\section{[Insert Table 1 about here]}

We tested the hypotheses about reprimands and absenteeism with moderated OLS regression. The results are in tables 2 and 3, respectively. We implemented logistic regression to test hypothesis about turnover, and the results are in table 4. Interaction effects were computed using centered predictors. Significant effects were plotted at one standard deviation above and below the mean. For clarity, we describe the results by outcome rather than hypotheses order. Reprimands. Main effect results show that none of the beliefs were related to reprimands, failing to support hypotheses 1a and 2a. Model 2 incorporates the interaction effect and showed significance for the interaction of toughness and stigma $(\beta=-.24, p<.05)$. The interaction plot in figure 3 depicts that toughness was related to reprimands, but only for people with low stigma consciousness. In support of hypothesis $4 \mathrm{a}$, beliefs in toughness led to lower reprimands among people high in stigma consciousness. Hypotheses $3 \mathrm{a}$ and $5 \mathrm{a}$, related to greed and wariness, were not supported. The results also showed a significant interaction for savvy and stigma consciousness on reprimands $(\beta=.22, p<.05)$. The plot in figure 3 shows that savvy was related to reprimands for people with high stigma consciousness, supporting hypothesis 6a.

[Insert Table 2 and Figure 1 about here]

Absenteeism. None of the beliefs had a significant main effect on absenteeism, failing to support hypotheses $1 \mathrm{~b}$ and $2 \mathrm{~b}$. Nonetheless, wariness beliefs had a significant correlation with absenteeism $(\mathrm{r}=.15, p<.05)$, suggesting that there is a relationship independent of other variables and controls. Furthermore, model 2 results show that the interaction of savvy and stigma was significant $(\beta=-.22, p<.05)$, although the plot shows that it was in the opposite 
direction of the one hypothesized. Savvy was positively related to absenteeism for people with low stigma consciousness. These results fail to support hypotheses $3 b, 4 b, 5 b$, and $6 b$.

[Insert Table 3 and Figure 2 about here]

Turnover. Main effects results showed that none of the beliefs were significantly related to turnover, failing to support hypotheses $1 \mathrm{c}$ and $2 \mathrm{c}$.

We did not hypothesize a main effect for stigma consciousness, but it is noteworthy that stigma consciousness had a significant positive correlation with turnover $(\mathrm{r}=.14, p<.05)$. Also, although the role of stigma consciousness on turnover in the regression was marginal $(\mathrm{B}=.40, p$ $<.10$ ), a post-hoc one-way ANOVA showed that leavers were more conscious of stigma than stayers $($ Means $=3.63,3.33, \mathrm{~F}=3.89, p<.05)$.

The interaction of greed and stigma consciousness was significantly related to turnover ( $\beta$ $=-1.09, \mathrm{p}<.01)$. Its plot showed that greed was negatively related to turnover for those with high stigma consciousness, supporting hypothesis $3 \mathrm{c}$. The interaction of stigma consciousness and toughness was not significant, and hypothesis $4 \mathrm{c}$ was not supported. The interaction of wariness and stigma consciousness was negatively related to turnover $(\beta=-.73,<.05)$, and the plot indicated that wariness was negatively related to turnover for those with high stigma consciousness, supporting hypothesis $5 \mathrm{c}$. The interaction of savvy and stigma consciousness was significantly related to turnover $(\beta=.89, p<.05)$. The plot indicated that savvy was positively related to turnover among those with high stigma consciousness, supporting hypothesis $6 \mathrm{a}$.

[Insert Table 4 and Figure 3 about here]

\section{Discussion}


We explored the prevalence of cultural beliefs and stigma about questionable conduct and their impact on organizational behavior using a sample of border-city Mexican police. This study relies on and joins past research exploring the occupational culture of police officers in developed (e.g., Manning, 1978; Van Maanen, 1975, 1978) and developing economies (e.g., Azaola, 2009; Botello \& Rivera, 2000; Cruz, 2010; Ivkovic, 2005).

We paid attention to the occupational, organizational, and national cultural context of the setting (Tsui, 2007). We also acknowledged the dark and subterranean nature of misconduct (Linstead et al., 2014; Skogan \& Frydl 2004) and the potential shortcomings of studying Mexican police behavior. Accordingly, we focused on the moral stigma of corruption and cultural beliefs related to questionable behavior rather than actual corrupt behavior. We presented a novel manner to assess related phenomena - the presence of stigma consciousness, cultural beliefs related to the rationalization and justification of misconduct, and their interactive effects on withdrawal behavior and reprimands. Triangulating quantitative and qualitative methodologies, we assessed the pervasiveness of cultural beliefs and stigma, and their role on punitive responses, absenteeism, and turnover. Qualitative phase findings helped us interpret quantitative phase results, which showed that, contingent upon stigma consciousness, cultural beliefs about questionable conduct influenced received reprimands, absenteeism, and turnover. Key Findings

Stigma consciousness. We addressed dirty work stigma as a catalyst, relying on past literature showing equivocal results for the role of stigma consciousness on withdrawal, identification, and solidarity (Pinel \& Paulin, 2005; Perrott \& Taylor, 1994; Westmarland, 2005). Consistent with this literature, we found that a corrupt and violent stigma is a central component of police officer consciousness. Qualitative phase findings indicated that the dirty work stigma was central to 
occupational identity, but that people implement strategies to enhance their self-image (Ashforth \& Krainer, 1999; Crocker \& Major, 1989). Police officers described strategies to rationalize it and reduce its adverse identity effects.

Reprimands. Consistent with our hypotheses, beliefs about savvy were related to more formal reprimands received, contingent upon high stigma consciousness. Guided by qualitative findings, this suggests that wit, "street-smarts," and personal connections were perceived to be guileful and cunning. The contingent role of stigma consciousness may mean that savvy is a desirable personal attribute, but only for high-status administrators and perhaps insiders who are deemed to use their savvy for the group's benefit. Also contingent on stigma consciousness, toughness beliefs were related to lower reprimands. In contrast to savvy, being tough was consistent with norms and led to lower disciplinary problems. This means that officers who believed in toughness did not deviate from organizational norms, or that their superiors overlooked their transgressions. Conversely, showing cowardice led to social rejection and punishment. In other words, normalized questionable conduct may not have led to reprimands, but misconduct that did not conform to norms was penalized.

Absenteeism. The results for absenteeism were more limited than those for the other two outcomes. Contrary to our hypotheses, people who were highly aware of their stigma and believed in savvy were less absent. One explanation would be that savvy helps stigma-aware people to reduce stress, cope with problems, and be healthier, resulting in less sick days. However, this would imply a similar effect with toughness as rugged individualism is a common police-stress coping strategy (Beehr et al., 1995), which was not present in our results. Qualitative study findings denoting the sale of formal sick-leave suggest alternative explanations. Either guile and low stigma consciousness was related to purchasing sick-leave, or people high 
in savvy and stigma awareness were able to be absent without having to resort to this practice. Given the negative connotations of savvy, this suggests that further research on stigma, questionable beliefs, and absenteeism would be fruitful.

Turnover. Quantitative results indicated that cultural beliefs about greed, wariness, and savvy predicted turnover, contingent upon stigma consciousness. Such results echo past work indicating that stigma fosters group solidarity and identification (e.g. Ashforth \& Kreiner, 1999; Westmarland, 2005). Officers who had beliefs justifying greed and were aware of their stigma stayed in the organization. Potentially, those who believed that there were lucrative opportunities in the organization stayed, even if such opportunities had questionable ethics. Also, wariness beliefs were negatively related to turnover among officers who were more stigma-conscious. Wariness implies justifying a culture of silence, but low wariness could also be based on trust and solidarity. Officers with low wariness beliefs and low stigma consciousness stayed in the organization. This implies that retention may depend on a complex balance between secrecy and trust. For instance, those who stayed may trust their colleagues, but be secretive with outsiders

In contrast, officers who believed in savvy and had high stigma consciousness were more likely to turnover. Qualitative phase results implied that savvy among rank-and-file officers is considered guile and cunning (e.g. "pasarse de listo" or being "too smart for their own good") for individual gain. We should also note that the interactive effect of savvy and stigma was similar for both reprimands and turnover. Although reprimands were not significantly related to turnover, these results reinforce the idea that savvy beliefs were inconsistent with cultural expectations. Thus, officers considered to be cunning may have been pushed away. Acknowledging the lack of job alternatives, another interpretation is that savvy is related to influential connections and the ability to pursue other job opportunities. 


\section{Limitations and directions for future research}

As in all studies, a number of limitations have to be considered. First, we were not able to differentiate between voluntary and involuntary turnover. The lack of alternatives and the socialization processes present in the setting may blur this distinction, and our hypotheses were related to turnover in general; however, this distinction may be relevant in future studies. Second, we were not able to measure actual or self-reported corrupt behavior given the theme's sensitive nature and sample characteristics. Nonetheless, we provided a novel manner to measure cultural beliefs about questionable conduct. Third, our measure of absenteeism relied on management records of excused absences. Organizational rules implied that absences should occur due to illness, but we had to consider the possibility that some absences are not documented and that participants engage in the purchase of sick leave. We interpreted the limited and counterintuitive findings with these possibilities in mind. Fourth, the theory behind stigma consciousness referenced mechanisms such as psychological withdrawal, group solidarity, cynicism, and identification, but we did not measure these variables in the quantitative phase. Nonetheless, qualitative phase findings suggested that these mechanisms were present.

The study was carried in a unique geographic and cultural context, and caution should be exercised when generalizing these results. Despite the setting's uniqueness, the cultural beliefs and behaviors studied are relevant to other nations, occupations, and organizations. For instance, the police and the military around the world share similar stigmas, but also a "heroic" component. This identity has implications for positive deviance behaviors such as principled dissent and whistle-blowing (Treviño et al., 2006). Toughness can become ruthlessness, but also foster the courage and valor to be ethical and not conform to corrupt organizational norms. Being conscious of a stigmatized identity but able to reject it from one's self-concept could incite 
principled dissent that resembles heroic behavior. Moreover, high-status professions mentioned by the respondents (e.g. politics, law, finance) possess negative stigmas. Our findings may generalize to those contexts, but future research in such settings would be fruitful.

The MCBQC employed the use of objective cultural artifacts - proverbs. The use of culturally relevant methodologies to capture implicit meaning, metaphorical nuance, and contextual idiosyncrasies is a fertile area. Proverbs are cultural artifacts, but have been used scantly (Bond et al., 2004; Shapin, 2001; Weber et al., 1988). Scholars can continue to use proverbs and beliefs to study sensitive subjects such as corruption, stigma, and ethics. This opens the door to future inquiry employing our scale in other Latin American organizations. Scholars may also develop similar proverb-based instruments to fit other languages and cultural contexts.

The results also suggest that the meaning of organizational metrics (e.g., absenteeism and reprimands) depend on context. Despite our unique setting, our results suggest that rich contextual description is helpful to quantitative analyses. Future mixed-method approaches can inform archival and self-reported measures to understand turnover, leader-member exchange, person-environment fit, and incentives driving (un)ethical behavior. Implementing longitudinal designs can reveal how beliefs and stigma awareness change as people are socialized or rejected from a group. Future research may also investigate cognitive and affective processes related to dirty work and stigmatized identities. Cultural beliefs can be studied at group and dyad (e.g. partners) levels to assess cultural strength and person-organization (or person-person) fit. Implications for Policy and Practice

This research ended at a time when the Mexican government embarked in an ongoing police cleanup involving confidence control testing and dismissals, which has had positive but also unintended adverse consequences (Sabet, 2012; Uildriks, 2010). Policy implications derived 
from the present study are consistent with radical organizational change involving "weeding out rotten apples" through dismissals. Nonetheless, our results further imply that such efforts could be futile if (un)ethical leadership and socialization processes are not addressed.

Our results also have an optimistic managerial implication, ratifying organizational change though development, training, and identity management. Management efforts to address misconduct and promote ethical behavior should address stigma and cultural beliefs, particularly in strong cultures. Occupational stigmas can stimulate a self-fulfilling prophecy by reinforcing misconduct and its rationalization and justification. Occupational identity strategies can serve to help workers distance themselves from the adverse aspects of stigmatized identity, and dysfunctional and corrupt behavior may be reduced through identity management.

Adverse stigmas influence the rationalization and justification of misconduct, but managers can use identity strategies to enhance group solidarity and identification by refocusing on positive occupational identity characteristics. Managing stigmatized identities can reduce the adverse-attribute salience, offer defensive tactics, and change occupational ideologies (Ashforth \& Krainer, 2014). Promoting or debunking beliefs can change attitudes and behavior, guide ethical decisions, and promote the retention of principled employees. Symbolic management through positive storytelling can be included into training and development. In addition, management can disseminate values and beliefs informally. These initiatives could include hero stories of people who exhibited positive but culturally consistent behavior, such as depicting the toughness of principled dissent. Given the importance of socialization and informal learning, managers should understand and manage members' formal and informal interaction. Lastly, the prevalence of top-down processes in corrupt organizations implies that concerted efforts to change culture and behavior must start at the top. 


\section{References}

Aditya, R. \& House, R. J. (2002). Interpersonal acumen and leadership across cultures: Pointers from the GLOBE study. In R. E. Riggio \& S. E. Murphy (Eds.), Multiple intelligences and leadership (pp. 215-240). Mahwah, NJ: Erlbaum.

Arellano-Gault, D., \& Lepore, W. (2011). Transparency reforms in the public sector: Beyond the new economics of organization. Organization Studies, 32, 1029-1050.

Arvey, R. D., \& Ivancevich, J. M. (1980). Punishment in organizations: A review, propositions, and research suggestions. Academy of Management Review, 5, 123-132.

Ashforth, B. E., \& Anand, V. (2003). The normalization of corruption in organizations. In R. M. Kramer \& B. Staw (Eds.), Research in Organizational Behavior, vol. 25 (pp. 1-52). Amsterdam: Elsevier.

Ashforth, B. E., Gioia, D. A., Robinson, S. L., \& Treviño, L. K. (2008) Re-viewing organizational corruption. Academy of Management Review, 33, 670-684.

Ashforth, B. E., \& Kreiner, G. E. (1999) "How can you do it?": Dirty work and the challenge of constructing a positive identity, The Academy of Management Review, 24, 413-434.

Ashforth, B. E., \& Kreiner, G. E. (2014). Dirty work and dirtier work: differences in countering physical, social, and moral stigma. Management and Organization Review, 10, 81-108.

Atwater, L. E., Waldman, D. A., Carey, J. A., \& Cartier, P. (2001). Recipient and observer reactions to discipline: Are managers experiencing wishful thinking? Journal of Organizational Behavior, 22, 249-270.

Azaola, E. (2009). The weaknesses of public security forces in Mexico City. Professional Issues in Criminal Justice, 4, 9-34.

Bailey, J., \& Paras, P. (2006). Perceptions and attitudes about corruption and democracy in Mexico. Mexican Studies/Estudios Mexicanos, 22, 57-82.

Beehr, T. A., Johnson, L. B., \& Nieva, R. (1995). Occupational stress: Coping of police and their spouses. Journal of Organizational Behavior, 16, 3-25.

Bittner, E. (1970). Functions of the Police in Modern Society. Washington, DC: NIMH.

Bluhm, D. J., Harman, W., Lee, T. W., \& Mitchell, T. R. (2011). Qualitative research in management: a decade of progress. Journal of Management Studies, 48, 1866-1891.

Bond, M. H., Leung, K., Au, A., Tong, K. K., De Carrasquel, S. R., Murakami, F., \& Sam, D. L. (2004). Culture-level dimensions of social axioms and their correlates across 41 cultures. Journal of Cross-Cultural Psychology, 35, 548-570. 
Botello, N. A., \& Rivera, A. L. (2000). Everything in this job is money: Inside the Mexican police. World Policy Journal, 17, 61-70.

Bowles, H. R., \& Gelfand, M. (2010). Status and the evaluation of workplace deviance. Psychological Science, 21, 49-54.

Britz, M. T. (1997). The police subculture and occupational socialization: Exploring individual and demographic characteristics. American Journal of Criminal Justice, 21, 127-146.

Butterfield, K. D., Treviño, L. K., \& Ball, G. A. (1996). Punishment from the manager's perspective: A grounded investigation and inductive model. Academy of Management Journal, 39, 1479-1512.

Cancino, J. M., \& Enriquez, R. (2004). A qualitative analysis of officer peer retaliation: Preserving the police culture. Policing: An International Journal of Police Strategies \& Management, 27, 320-340.

Cassell, C., \& Symon, G. (2004). Essential guide to qualitative methods in organizational research. Thousand Oaks, CA: Sage.

Cohen, D., Nisbett, R. E., Bowdle, B. F., \& Schwarz, N. (1996). Insult, aggression, and the southern culture of honor: an "experimental ethnography". Journal of Personality and Social Psychology, 70, 945-960.

Costas, J. \& Grey, C. (2014). Bringing secrecy into the open: Towards a theorization of the social processes of organizational secrecy. Organization Studies, 23, 1423-1447.

Creswell, J. W., \& Plano Clark, V. L. (2011). Designing and conducting mixed methods research $\left(2^{\text {nd }}\right.$ ed $)$. Sage: Thousand Oaks, CA.

Crocker, J., \& Major, B. (1989). Social stigma and self-esteem: The self-protective properties of stigma. Psychological Review, 96, 608-630.

Cruz, J. M. (2010). Police misconduct and democracy in Latin America. Americas Barometer Insights, 33, 1-5.

Daly, C., Heinle, K., \& Shirk, D. A. (2012). Armed with impunity: Curbing military human rights abuses in Mexico. Special Report of the Trans-Border Institute. San Diego: University of San Diego.

Dick, P. (2005). Dirty work designations: How police officers account for their use of coercive authority. Human Relations, 58, 1363-1390.

Drew, S. K., \& Hulvey, M. (2007). Cops, crimes, and community policing. In S. K. Drew, M. Mills, \& B. M. Gassaway (Eds.). Dirty work: The Social Construction of Taint, (pp. 169-193). Waco, TX: Baylor University Press. 
Duarte, F. (2006). Exploring the interpersonal transaction of the Brazilian jeitinho in bureaucratic contexts. Organization, 13, 509-527.

Frühling, H. (2007). The impact of international models of policing in Latin America: The case of community policing. Police Practice and Research, 8, 125-144.

Gabriel, Y. (2012). Organizations in a state of darkness: Towards a theory of organizational miasma. Organization studies, 33, 1137-1152.

Gino, F., \& Pierce, L. (2009). The abundance effect: Unethical behavior in the presence of wealth. Organizational Behavior and Human Decision Processes, 109, 142-155.

Godfrey, R., Lilley, S., \& Brewis, J. (2012). Biceps, bitches and borgs: Reading Jarhead's representation of the construction of the (masculine) military body. Organization Studies, 33, 541-562.

Goffman, E. (1963). Stigma: Notes on the management of spoiled identity. Englewood Cliffs, NJ: Prentice-Hall.

Gordon, R., Clegg, S., \& Kornberger, M. (2009). Embedded ethics: discourse and power in the New South Wales police service. Organization Studies, 30, 73-99.

Greve, H. R., Palmer, D., \& Pozner, J. E. (2010). Organizations gone wild: The causes, processes, and consequences of organizational misconduct. Academy of Management Annals, 4, 53-107.

Griffin, R. W., \& Lopez, Y. P. (2005). "Bad behavior" in organizations: A review and typology for future research. Journal of Management, 31, 988-1005.

Hofstede, G. (1998). Attitudes, values and organizational culture: Disentangling the concepts. Organization studies, 19, 477-493.

Husted, B. W. (2002). Culture and international anti-corruption agreements in Latin America. Journal of Business Ethics, 37, 413-422.

Ivkovic, S. K. (2005). Police (mis)behavior: A cross-cultural study of corruption seriousness. Policing: An International Journal of Police Strategies \& Management, 28, 546-566.

Jong-Sung, Y., \& Khagram, S. (2005). A comparative study of inequality and corruption. American Sociological Review, 70, 136-157.

Kammeyer-Mueller, J. D., Simon, L. S., \& Rich, B. L. (2012). The Psychic Cost of Doing Wrong Ethical Conflict, Divestiture Socialization, and Emotional Exhaustion. Journal of Management, 38, 784-808. 
Kouchaki, M., Smith-Crowe, K., Brief, A. P., \& Sousa, C. (2013). Seeing green: Mere exposure to money triggers a business decision frame and unethical outcomes. Organizational Behavior and Human Decision Processes, 121, 53-61.

Kreiner, G. E., Ashforth, B. E., \& Sluss, D. M. (2006). Identity dynamics in occupational dirty work: Integrating social identity and system justification perspectives. Organization Science, 17, 619-636.

Lai, J. Y., Chan, K. W., \& Lam, L. W. (2013). Defining who you are not: The roles of moral dirtiness and occupational and organizational disidentification in affecting casino employee turnover intention. Journal of Business Research, 66, 1659-1666.

LaRose, AP \& Maddan, SA (2009). Reforming la policía: Looking to the future of policing in Mexico. Police Practice and Research, 10, 333-348.

Lester, D., \& Brink, W. T. (1985). Police solidarity and tolerance for police misbehavior. Psychological Reports, 57, 326-326.

Leung, K., Bond, M. H., de Carrasquel, S. R., Muñoz, C., Hernández, M., Murakami, F., \& Singelis, T. M. (2002). Social axioms: The search for universal dimensions of general beliefs about how the world functions. Journal of Cross-Cultural Psychology, 33, 286-302.

Linstead, S., Maréchal, G., \& Griffin, R. W. (2014). Theorizing and researching the dark side of organization. Organization Studies, 35, 165-188.

Major, B., \& O'Brien, L.T. (2005). The social psychology of stigma. Annual Review of Psychology, 56, 393-421.

Manning, P. K. (1978). Lying, secrecy, and social control. In P. K. Manning and J. Van Maanen (Eds.) Policing: A View from the Streets (pp. 115-128). New York: Random House.

Manning, P. K. (2008). Goffman on organizations. Organization Studies, 29, 677-699.

Mars, G. (1982). Cheats at work: An anthropology of occupational crime. London: Allen and Unwin.

Newburn, T., \& Webb, B. (1999). Understanding and preventing police corruption: Lessons from the literature. London: Research Development Statistics.

Paredes, A. (1971). The United States, Mexico, and" Machismo". Journal of the Folklore Institute, 8, 17-37.

Park, H., Blenkinsopp, J., Oktem, M. K., \& Omurgonulsen, U. (2008). Cultural orientation and attitudes toward different forms of whistleblowing: A comparison of South Korea, Turkey, and the UK. Journal of Business Ethics, 82, 929-939. 
Pérez Martínez, H. (2002). Los refranes del hablar mexicano en el siglo XX [The proverbs of Mexican speech in the XX century]. México: El Colegio de Michoacán.

Peterson, M. F., \& Søndergaard, M. (2011). Traditions and transitions in quantitative societal culture research in organization studies. Organization Studies, 32, 1539-1558.

Perrott, S. B., \& Taylor, D. M. (1994). Ethnocentrism and authoritarianism in the police: Challenging stereotypes and reconceptualizing ingroup identification. Journal of Applied Social Psychology, 24, 1640-1664.

Pinel, E. C. (1999). Stigma consciousness: The psychological legacy of social stereotypes. Journal of Personality and Social Psychology, 76, 114-128.

Pinel, E. C., \& Paulin, N. (2005). Stigma consciousness at work. Basic and Applied Social Psychology, 27, 345-352.

Pinto, J., Leana, C. R., \& Pil, F. K. (2008). Corrupt organizations or organizations of corrupt individuals? Two types of organizational-level corruption. Academy of Management Review, 33, 685-709.

Podsakoff, P. M., Bommer, W. H., Podsakoff, N. P., \& MacKenzie, S. B. (2006). Relationships between leader reward and punishment behavior and subordinate attitudes, perceptions, and behaviors: A meta-analytic review of existing and new research. Organizational Behavior and Human Decision Processes, 99, 113-142.

Prenzler, T., \& Drew, J. (2013). Women police in post-Fitzgerald Queensland: A 20 year review. Australian Journal of Public Administration, 72, 459-472.

Punch, M. (2003). Rotten orchards: "Pestilence," police misconduct and system failure. Policing and Society, 13, 171-196.

Robinson, S. L., \& Bennett, R. J. (1995). A typology of deviant workplace behaviors: A multidimensional scaling study. Academy of Management Journal, 38: 555-572.

Rosenbaum, M. S., \& Kuntze, R. (2003). The relationship between anomie and unethical retail disposition. Psychology \& Marketing, 20, 1067-1093.

Rubinstein, J. (1973). City police. New York: Hill and Wang.

Sabet, D. (2012). Police reform in Mexico: Informal politics and the challenge of institutional change. Palo Alto, CA: Stanford University Press.

Sanchez, J. I., Gomez, C., \& Wated, G. (2008). A value-based framework for understanding managerial tolerance of bribery in Latin America. Journal of Business Ethics, 83, 341-352. 
Sarchione, C. D., Cuttler, M. J., Muchinsky, P. M. \& Nelson-Gray, R. O. (1998). Prediction of dysfunctional job behaviors among law enforcement officers. Journal of Applied Psychology, 83, 904-912.

Schaffer, B. S., \& Riordan, C. M. (2003). A review of cross-cultural methodologies for organizational research: A best-practices approach. Organizational Research Methods, 6, 169-215.

Schein, E. H. (2006). From brainwashing to organizational therapy: A conceptual and empirical journey in search of 'systemic' health and a general model of change dynamics. A drama in five acts. Organization studies, 27, 287-301.

Schneider, B. (1987). The people make the place. Personnel Psychology, 40, 437-453.

Sellers, J. M. (1994). Folk wisdom of Mexico. San Francisco: Chronicle Books.

Shapin, S. (2001). Proverbial economies: How an understanding of some linguistic and social features of common sense can throw light on more prestigious bodies of knowledge, science for example. Social Studies of Science, 31, 731-769.

Skogan, W, \& Frydl K. (2004). Fairness and Effectiveness in Policing: The Evidence. Washington, DC: The National Academies Press.

Suárez de Garay, M. E. S. (2005). Armados, enrejados, desconfiados. Tres breves lecturas sobre la cultura policial mexicana. Política y sociedad [Armed, behind bars, and distrustful... three short lectures on Mexican police culture. Politics and Society], 42, 87-102.

Tashakkori, A., \& Teddlie, C. (2010). Sage handbook of mixed methods in social \& behavioral research $\left(2^{\text {nd }}\right.$ ed) Thousand Oaks, CA: Sage.

Treviño, L. K., Weaver, G. R., \& Reynolds, S. J. (2006). Behavioral ethics in organizations: A review. Journal of Management, 32, 951-990.

Trice, H. M. (1993). Occupational subcultures in the workplace. Ithaca, NY: Cornell University Press.

Trostle, L. C. (2005). Police solidarity and tolerance for police misbehavior, revisited. Psychological Reports, 96, 26-28.

Tsui, A. S. (2007). From homogenization to pluralism: International management research in the academy and beyond. Academy of Management Journal, 50, 1353-1364.

Uildriks, N. (2010). Mexico's unrule of law: Implementing human rights in police and judicial reform under democratization. Lanham, MA: Lexington Books. 
Van Maanen, J. (1975). Police socialization: A longitudinal examination of job attitudes in an urban police department. Administrative Science Quarterly, 20, 207-228.

Van Maanen, J. (1978). Kinsmen in repose: Occupational perspectives of patrolmen. In P. K. Manning and J. Van Maanen (Eds.) Policing: A View from the Streets (pp. 115-128). New York: Random House.

Wang, L., \& Murnighan, J. K. (2011). On Greed. Academy of Management Annals, 5, 279-316.

Warren, D. E. (2003). Constructive and destructive deviance in organizations. Academy of Management Review, 28, 622-632.

Weber, E. U., Hsee, C. K., \& Sokolowska, J. (1998). What folklore tells us about risk and risk taking: Cross-cultural comparisons of American, German, and Chinese proverbs. Organizational Behavior and Human Decision Processes, 75, 170-186.

Welch, C., Piekkari, R., Plakoyiannaki, E., \& Paavilainen-Mäntymäki, E. (2011). Theorising from case studies: Towards a pluralist future for international business research. Journal of International Business Studies, 42, 740-762.

Westmarland, L. (2005). Police ethics and integrity: Breaking the blue code of silence. Policing and Society, 15, 145-165.

Wolfe, S. E., \& Piquero, A. R. (2011). Organizational justice and police misconduct. Criminal Justice and Behavior, 38, 332-353.

Xin, K. K., \& Pearce, J. L. (1996). Guanxi: Connections as substitutes for formal institutional support. Academy of Management Journal, 39, 1641-1658.

Yau, O. H. M. (1994). Consumer behaviour in China: Customer satisfaction and cultural values, London: Routledge. 
Table 1

Descriptive Statistics and Correlations

\begin{tabular}{llccccccccccccc}
\hline & Variables & Mean & S.D. & 1 & 2 & 3 & 4 & 5 & 6 & 7 & 8 & 9 & 10 & 11 \\
\hline 1 & Reprimands & 1.18 & 1.79 & & & & & & & & & & \\
2 & Absenteeism & .84 & 1.26 & -.03 & & & & & & & & & \\
3 & Turnover & -- & -- & -.03 & $.18^{*}$ & & & & & & & & \\
4 & Tenure & 7.44 & 6.79 & .10 & $.15^{*}$ & .09 & & & & & & & \\
5 & Gender & -- & -- & .09 & .01 & $.17^{*}$ & $-.14^{* *}$ & & & & & & \\
6 & Workplace Injury & -- & -- & -.01 & $.28^{*}$ & .13 & $.25^{* *}$ & -.06 & & & & & \\
7 & Greed & 2.22 & .86 & -.07 & -.06 & .06 & $.12^{*}$ & -.02 & .03 & $(.85)$ & & & \\
8 & Toughness & 2.77 & .97 & -.08 & -.09 & .09 & .04 & .04 & .04 & $.48^{* *}$ & $(.81)$ & & \\
9 & Wariness & 3.00 & .94 & -.05 & .06 & .09 & .09 & -.03 & .09 & $.41^{* *}$ & $.62^{* *}$ & $(.77)$ & \\
10 & Savvy & 3.23 & 1.00 & -.02 & .00 & .07 & .07 & -.04 & .02 & $.50^{* *}$ & $.56^{* *}$ & $.56^{* *}$ & $(.70)$ \\
11 & Stigma & 3.45 & .94 & -.01 & -.07 & $.14^{*}$ & .06 & -.09 & .08 & $.40^{* *}$ & $.36^{* *}$ & $.35^{* *}$ & $.24^{* *}$ & $(.70)$ \\
& Consciousness & & & & & & & & & & & & & \\
\hline
\end{tabular}

Note: $\mathrm{N}=352(\mathrm{~N}=192$ for variables 1-3) Two-tailed tests. Coefficient alphas are in parentheses along the diagonal. Absenteeism is a logarithmic transformation. Turnover is coded left $=1$, stayed $=0$. Gender is coded female $=1$, male $=0$. Workplace injury is coded yes $=1$, no $=0 .{ }^{*} p<.05 . * * p<.01$ 
Table 2

Regression Analyses Results for Reprimands

\begin{tabular}{|c|c|c|}
\hline Variables & Model 1 & Model 2 \\
\hline Tenure & .11 & .12 \\
\hline Gender & .05 & .07 \\
\hline Greed & -.08 & -.10 \\
\hline Toughness & -.08 & -.01 \\
\hline Wariness & -.03 & -.04 \\
\hline Savvy & .08 & .03 \\
\hline Stigma & .07 & .05 \\
\hline \multicolumn{3}{|l|}{ Interactions } \\
\hline Greed x Stigma Consciousness & & -.01 \\
\hline Toughness x Stigma Consciousness & & $-.24 *$ \\
\hline Wariness x Stigma Consciousness & & -.03 \\
\hline Savvy x Stigma Consciousness & & $.22 *$ \\
\hline $\mathrm{R}^{2}$ & .02 & .07 \\
\hline $\mathrm{R}^{2}$ change & & $.05^{*}$ \\
\hline
\end{tabular}


Table 3

Regression Analyses Results for Absenteeism

\begin{tabular}{|c|c|c|}
\hline Variables & Model 1 & Model 2 \\
\hline Tenure & .13 & .12 \\
\hline Gender & .04 & .07 \\
\hline On-the-job Injury & $.25 * *$ & $.25 * *$ \\
\hline Greed & -.08 & -.06 \\
\hline Toughness & -.16 & -.22 \\
\hline Wariness & $.22 \dagger$ & .21 \\
\hline Savvy & -.00 & .02 \\
\hline Stigma Consciousness & -.13 & -.11 \\
\hline \multicolumn{3}{|l|}{ Interactions } \\
\hline Greed x Stigma Consciousness & & -.06 \\
\hline Toughness x Stigma Consciousness & & .24 \\
\hline Wariness x Stigma Consciousness & & -.08 \\
\hline Savvy x Stigma Consciousness & & $-.22 *$ \\
\hline $\mathrm{R}^{2}$ & .13 & .17 \\
\hline $\mathrm{R}^{2}$ change & & $.04 *$ \\
\hline
\end{tabular}


Table 4

Logistic Regression Analysis Results for Turnover

\begin{tabular}{|c|c|c|c|c|}
\hline Variables & $\mathrm{B}$ & $\mathrm{SE}$ & Wald & $\begin{array}{c}\text { Model } \\
\text { Statistics }\end{array}$ \\
\hline \multicolumn{5}{|l|}{ Step 1} \\
\hline Tenure & .03 & .03 & 1.55 & \\
\hline Gender & $1.68 * *$ & .59 & 8.00 & \\
\hline On-the-job Injury & .55 & .41 & 1.75 & \\
\hline Greed & -.18 & .27 & .47 & \\
\hline Toughness & -.03 & .27 & .01 & \\
\hline Wariness & .05 & .26 & .04 & \\
\hline Savvy & .16 & .25 & .41 & \\
\hline Stigma Consciousness & $.40 \dagger$ & .22 & 3.37 & \\
\hline -2 Log Likelihood Estimate & & & & 197.67 \\
\hline Chi Square & & & & 15.18 \\
\hline Pseudo R ${ }^{2}$ & & & & .11 \\
\hline \multicolumn{5}{|l|}{ Model 1 - Step 2} \\
\hline Tenure & .04 & .03 & 2.11 & \\
\hline Gender & $1.94 * *$ & .67 & 8.50 & \\
\hline On-the-job Injury & .65 & .43 & 2.25 & \\
\hline Greed & .22 & .32 & .46 & \\
\hline Toughness & -.08 & .37 & .04 & \\
\hline Wariness & .32 & .29 & 1.27 & \\
\hline Savvy & -.21 & .31 & .45 & \\
\hline Stigma & .37 & .26 & 2.03 & \\
\hline Greed x Stigma Consciousness & $-1.09 * *$ & .40 & 7.29 & \\
\hline Toughness x Stigma Consciousness & -.02 & .37 & .00 & \\
\hline Wariness x Stigma Consciousness & $-.73 *$ & .30 & 5.71 & \\
\hline Savvy x Stigma Consciousness & $.89^{*}$ & .35 & 6.34 & \\
\hline -2 Log Likelihood Estimate & & & & 180.22 \\
\hline Chi Square & & & & 14.38 \\
\hline Pseudo R ${ }^{2}$ & & & & .24 \\
\hline
\end{tabular}

Note: Pseudo $\mathrm{R}^{2}$ computed using Nagelkerke method. Overall correct classification of stayers and leavers was $75.4 \%, \dagger \mathrm{p}<.10, * \mathrm{p}<.05, * * \mathrm{p}<.01, * * * \mathrm{p}<.001$ 
1

2

3

4

5

6

7

8

9

10

11

12

13

14

15

16

17

18

19

20

21

22

23

24

25

26

27

28

29

30

31

32

33

34

35

36

37

38

39

40

41

42

43

44

45

46

47

48

49

50

51

52

53

54

55

56

57

58

59

60
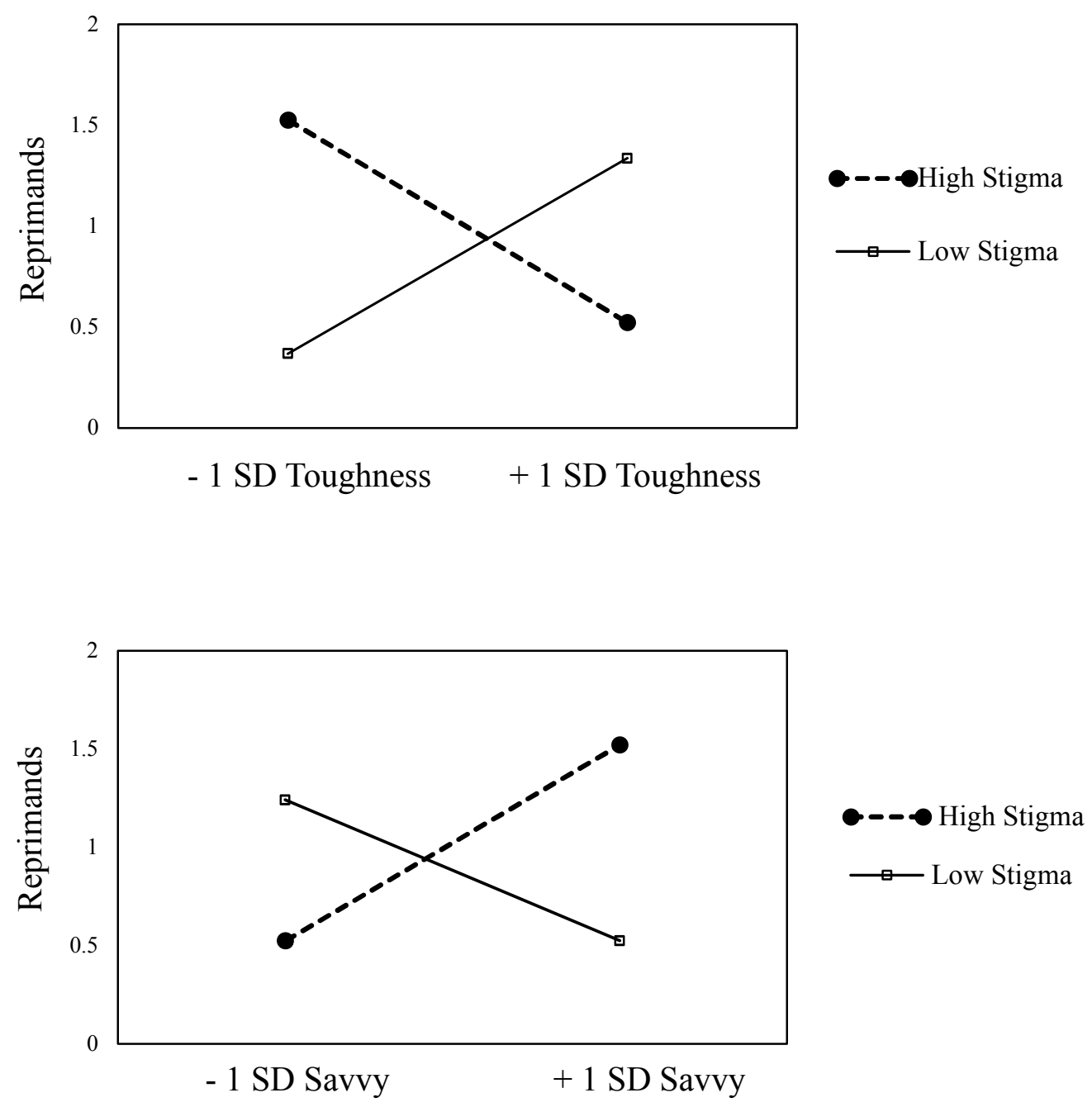

Figure 1. The relationship between beliefs about questionable conduct and reprimands moderated by stigma consciousness. 


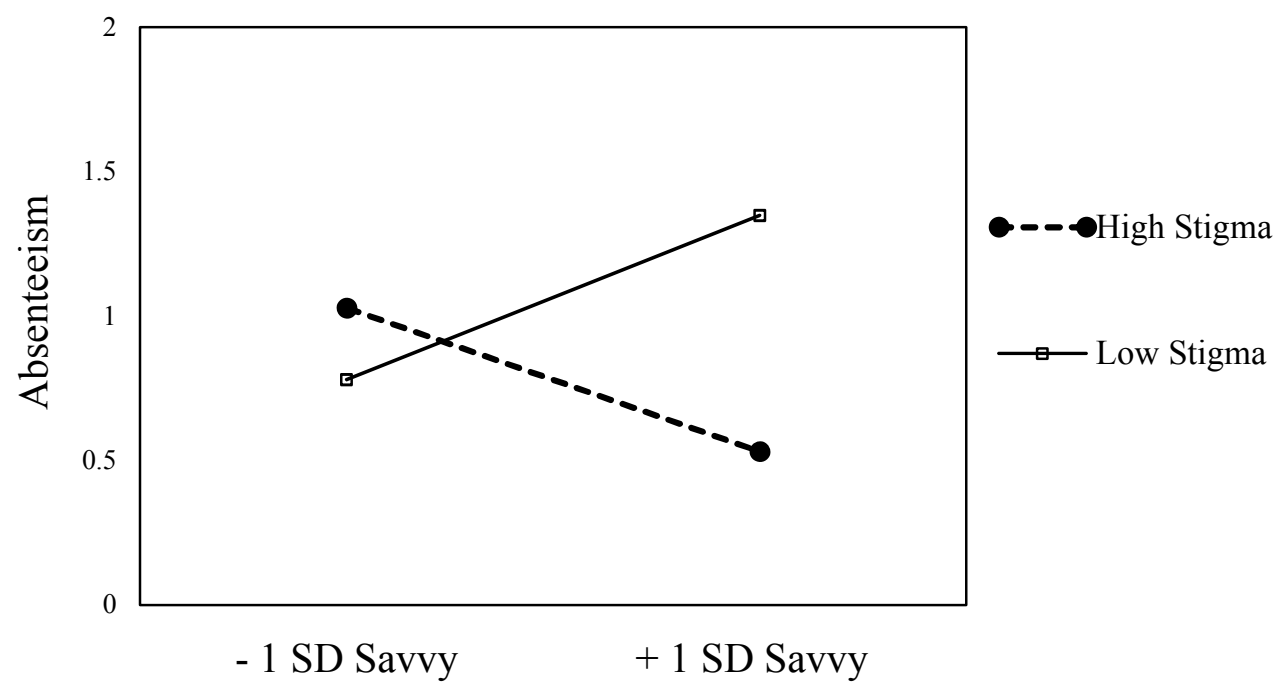

Figure 2. The relationship between beliefs about questionable conduct and absenteeism moderated by stigma consciousness 




Figure 3. The relationship between beliefs about questionable conduct and (log odds) turnover moderated by stigma consciousness. 
Appendix

The Mexican Cultural Beliefs about Questionable Conduct scale

\begin{tabular}{|c|c|}
\hline Proverb & EFA Factor Loading \\
\hline \multicolumn{2}{|l|}{ Greed } \\
\hline God gives us money, only fools work to get it & 0.69 \\
\hline Whatever falls here stays here & 0.68 \\
\hline The one who pays, rules & 0.67 \\
\hline The pig with the biggest mouth gets the best corn & 0.65 \\
\hline The dog dances with money (money can accomplish anything) & 0.63 \\
\hline The smart eat from the dumb, and the dumb only from their work & 0.59 \\
\hline Even if coming from dirty hands, money always smell like roses & 0.59 \\
\hline For those who have money, even their farts smell good & 0.58 \\
\hline \multicolumn{2}{|l|}{$\begin{array}{r}\text { Toughness } \\
\text { Tough }\end{array}$} \\
\hline Cowards never fill graveyards (as if stated by a valiant person) & 0.71 \\
\hline Fear is like blood, it runs in all veins (as if stated by a valiant person) & 0.64 \\
\hline If your tail is made of grass, don't approach the fire & 0.61 \\
\hline If they smell that you are scared you are screwed & 0.56 \\
\hline For a coward, fear is mere prudence (as if stated by a valiant person) & 0.55 \\
\hline \multicolumn{2}{|l|}{ Wariness } \\
\hline You should not stir the waters you do not intend to drink (stay away from what is none of your business) & 0.71 \\
\hline You don't judge what you can't see & 0.70 \\
\hline Shit: either try it or cover it & 0.63 \\
\hline Under distrust you have security & 0.63 \\
\hline For trust and secrets there are no subjects (trust no one) & 0.49 \\
\hline \multicolumn{2}{|l|}{ Savy } \\
\hline Better to be in good standing than in good sitting (good sitting means clout, good sitting means a job title) & 0.68 \\
\hline Better to have guile than to be strong & 0.63 \\
\hline Shame is to steal and get caught (but it is not shameful to steal and not get caught) & 0.61 \\
\hline Without oil, machines don't run (do not do a favor without reciprocity or gain) & 0.57 \\
\hline
\end{tabular}

Note: The Spanish version is available upon request. Wording in parentheses is for interpretation and not part of the scale. 